\title{
Disappearing cervical disc
}

\section{Case report}

\section{Richard M. Westmark, M.D., Kaye D. Westmark, M.D., and Volker K. H. Sonntag, M.D.}

Division of Neurological Surgery, Barrow Neurological Institute, St. Joseph's Hospital and Medical Center, Phoenix, Arizona

The authors report the case of a 48-year-old woman who experienced spontaneous resolution of a large herniated disc at C6-7. Spontaneous resolution of a herniated lumbar disc was first documented by computerized tomography. This case is another example of a rare spontaneous resolution of a cervical disc herniation documented by magnetic resonance imaging.

Key Words * cervical spine * disc

The spontaneous resolution of herniated lumbar discs is a well-established phenomenon.[1,2,4-7,9] In 1985, Teplick and Haskin[9] first documented the spontaneous resolution of a lumbar disc by computerized tomography. Since that time, the spontaneous resolution in several cases of cervical disc herniations has also been documented by computerized tomography.[8] The following case represents a rare instance of magnetic resonance (MR) imaging documenting the spontaneous resolution of a large cervical disc herniation.

\section{CASE REPORT}

This 48-year-old, right-handed woman developed right-sided scapular pain after lifting boxes. She was treated with steroids and her condition improved. Four months later her symptoms recurred and she presented for MR imaging (Fig. 1). The initial MR image revealed loss of normal cervical lordosis and degenerative changes at the C5-6 and C6-7 levels. A posterior disc herniation was visible at C5-6, and a larger volume disc herniation at C6-7 was compressing the spinal cord. Another small herniation was present at the C3-4 level. The patient was treated at another institution and was given a second course of oral steroids. 


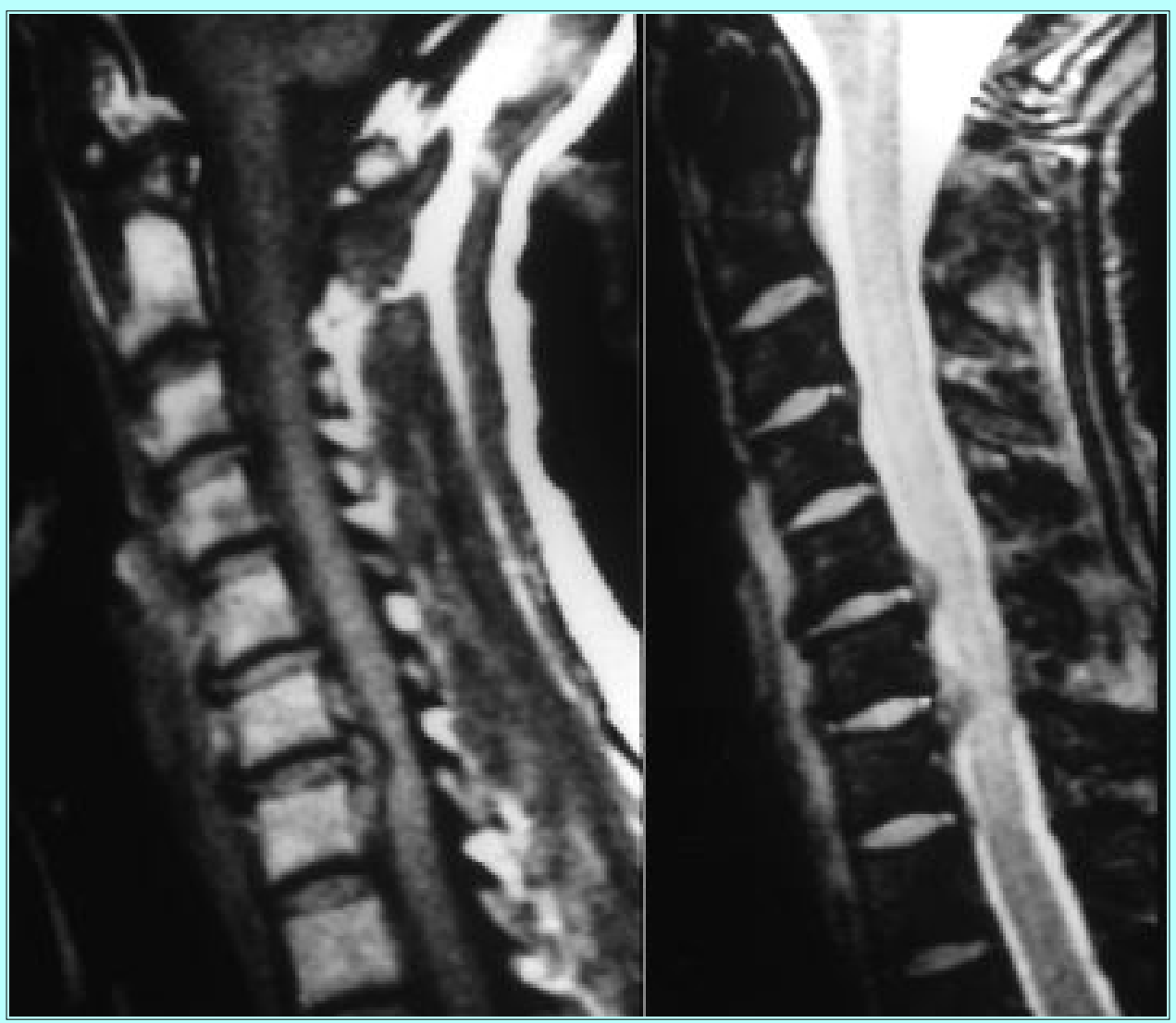

Fig. 1. Magnetic resonance images, sagittal T1-weighted (left) and gradient refocused T2-weighted (right) revealing large C5-6 and C6-7 disc extrusions compressing the anterior aspect of the spinal cord.

Two weeks after the initial MR imaging study, the patient was scheduled for surgery. On the day of surgery, she reported that her symptoms had resolved and declined surgery. She was relatively free of symptoms the next 6 months until she awoke with weakness of her left arm and occipital headaches. She underwent another MR imaging study.

The patient presented to our institution for evaluation 2 years after her initial symptoms. At that time she complained only of intermittent interscapular pain, which she described as insignificant. She had no bowel or bladder dysfunction or difficulty with gait. Otherwise, her medical history was unremarkable. On physical examination she had full range of motion in her neck. Her motor examination revealed 5/5 strength throughout, and her sensation to pinprick, light touch, and vibration was intact. All reflexes were brisk and symmetric. The Babinski sign was negative. There was a suggestion of Hoffmann's sign on her left side. Her gait was normal. Follow-up MR imaging again demonstrated loss of normal cervical lordosis; however, the C6-7 disc herniation had resolved dramatically and, to a lesser extent, so had the herniations at the C3-4 and C5-6 levels (Fig. 2). 


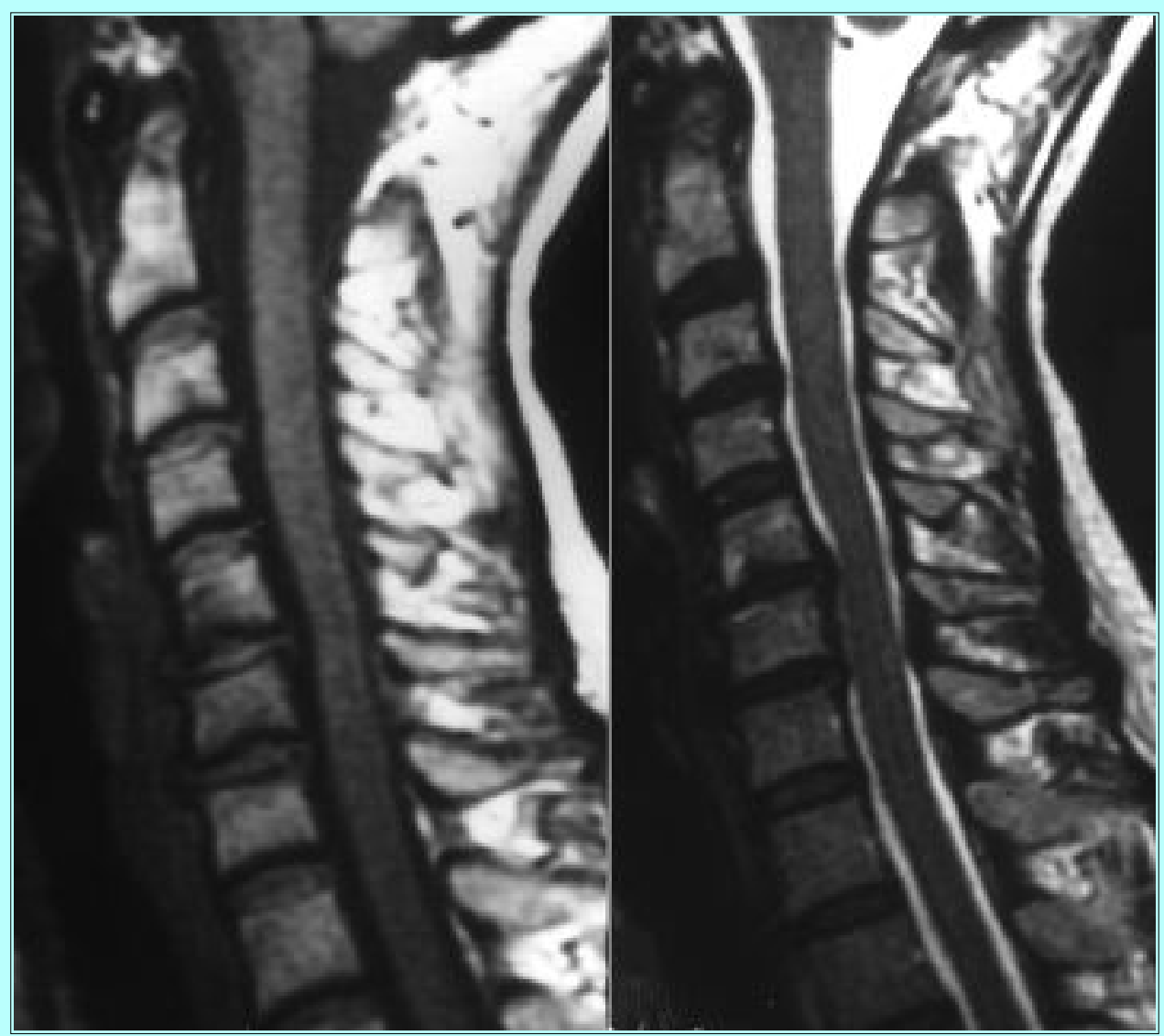

Fig. 2. Magnetic resonance images, sagittal T1-weighted (left) and T2-weighted (right) obtained 18 months after the patient's initial presentation, revealing internal resorption of the extruded disc material with minimal effacement of the cerebrospinal fluid anterior to the spinal cord.

\section{DISCUSSION}

This case documents, by MR imaging, the rare spontaneous resolution of a large herniated cervical disc.[3] The resolution of the disc herniation on MR imaging corresponded to the clinical resolution of the patient's symptoms. We do not advocate conservative management of a large herniated cervical disc that becomes symptomatic with myelopathy; however, this case illustrates the potential for the spontaneous regression of even significantly sized herniated cervical discs. The finding underscores that the potential for regression should be considered in the evaluation and management of any patient with a herniated cervical disc.

\section{References}

1. Didry C, Lopez P, Baixas P, et al: Hernies discales lombaires non opérées. Evolution clinique et tomodensitométrique. Presse Med 20:299-302, 1991

2. Hernandez CS: The current treatment in spontaneous recovery of the herniated disk. Anales de la Real Acad Nacion Med 108:227-244, 1991

3. Krieger AJ, Maniker AH: MRI-documented regression of a herniated cervical nucleus pulposus: A case report. Surg Neurol 37:457-459, 1992

4. Lapuyade G, Loustau JM: Régression spontanée des hernies discales. Apropos de observations. J 
Radiol 70:697-702, 1989

5. Lutman M, Girelli G: Spontaneous regression of lumbar disc hernia. R Radiol Med 81:225-227, 1991

6. Scale D, Zichner L: Spontanverlauf beim lumbalen Bandscheibenvorfall. Orthopade 23:236-242, 1994

7. Sei A, Nakamura T, Fukuyama S, et al: Régression spontanée des hernies du nucleus pulposus au nireau tombaire. 4 cas suivis par des IRM répétées. Rev Chir Orthop Reparatrice Appar Mot 80:144-149, 1994

8. Teplick JG: Lumbar Spine CT and MRI. Philadelphia: JB Lippincott, 1992, pp 143-152

9. Teplick JG, Haskin ME: Spontaneous regression of herniated nucleus pulposus. AJR 145:371-375, 1985

Manuscript received June 27, 1996.

Accepted in final form November 14, 1996.

Address correspondence to: Volker K. H. Sonntag, M.D., c/o Neuroscience Publications, Barrow Neurological Institute, 350 West Thomas Road, Phoenix, Arizona 85013-4406. E-mail: neuropub@mha.chw.edu. 